\title{
Formulation and Evaluation of Mesoporous Silica Nanoparticle Loaded Fast Dissolving Tablet of Tamoxifen
}

\author{
V. V. JADHAV* \\ Quality Assurance Department, Appasaheb Birnale College of Pharmacy, Sangli, Maharashtra 416416, India
}

\section{Jadhav et al.: Formulation and Evaluation of MSN Loaded FDT of Tamoxifen}

\begin{abstract}
Breast cancer is a cancer which has significant societal impact because it generally affects the young age people. Tamoxifen is Biopharmaceutical Classification System class II drug. This active pharmaceutical ingredient have problem with solubility. Most of the anti-cancerous drugs have problem with solubility because of their complicated structures. To deal with this problem mesoporous silica nanoparticles of tamoxifen are prepared. Drug entrapped in mesoporous structure which is having size less than 200 nm. It leads to improvement in solubility and further bioavailability. Various studies after formulation show improvement in solubility and decrease in particle size. Further fast dissolving tablet is prepared to improve bioavailability. Pre compression studies and post compression studies show tablet dissolve within 30 s. Hence mesoporous silica nanoparticles are best way to improve solubility.
\end{abstract}

Key words: Nanoparticles, fast dissolving tablet, tamoxifen, bioavailability

Mesoporous Silica Nanoparticle (MSN) invented in 1992 by Mobil R and D Corporation. They synthesized mesoporous solids from alumino silicate gels byutilizing liquefied crystal template mechanism. To achieve a greater affinity towards target site, more complex structure of drug is obtained. These drugs having high activity are mostly water insoluble or poorly solubility in water. $90 \%$ of active pharmaceutical ingredient (API) is having low water solubility. Various methods are used to enhance bioavailability of drug. Example: Solid dispersion, size reduction, nanoparticles, etc. Out of this methods MSN method is extensively used recently. They have a scope in various types of cancer ${ }^{[1-3]}$.

Silica precursor and micelle templates are used for development of mesoporous structure. After development of MSN, drug is loaded in silica nanoparticles. It leads to enhancement of bioavailability of drug. Bioactive molecule is trapped into mesoporous silica. It is called as MSN. API is delivered to site of action. It has unique advantages like tunable pore size, great constancy and inflexible framework, uniform pore size, high pore volume and greater surface area. Hence MSN are widely used now a days to enhance bioavailability of $\operatorname{drug}^{[4,5]}$.

MSN generally have a 2-50 nm pore volume. Different types of nanoparticles have a different particle size

*Address for correspondence

E-mail: vinayajadhav111@gmail.com

January-February 2021 to produce desirable effects. Generally particle size maintained below is $200 \mathrm{~nm}$ to enhance bioavailability ${ }^{[6]}$.

\section{MATERIALS AND METHODS}

\section{Materials:}

Tamoxifen purchased from Neon Laboratories Ltd, Kandiwali, Mumbai. Cetyl trimethyl ammonium bromide (CTAB) purchased from Advent Chem Bio Pvt. Ltd, Bhiwandi. Tetraethyl orthosilicate (TEOS) purchased from Dr. Khan industrial consultant Pvt. Ltd. Ratnagiri. Mannitol purchased from Sankalp Healthcare and Allied Products Pvt. Ltd, Karad. Microcrystalline cellulose purchased from DFE Pharma, Bangalore. Sodium starch glycolate, ethanol, magnesium stearate, talc purchased from research lab, Mumbai ${ }^{[7-10]}$.

\section{Preformulation study:}

Preformulation study is used to check purity of drug. Study also performed to check compatibility of API and excipients. This is an open access article distributed under the terms of the Creative
Commons Attribution-NonCommercial-ShareAlike 3.0 License, which
allows others to remix, tweak, and build upon the work non-commercially,
as long as the author is credited and the new creations are licensed under
the identical terms

Accepted 13 February 2021

Revised 29 November 2020

Received 17 August 2020 Indian J Pharm Sci 2021;83(1):32-38 


\section{Authentication:}

Authentication of excipients is performed using Fouriertransform infrared (FTIR) spectroscopy, melting point.

Fourier-transform infrared (FTIR) spectroscopy; FTIR performed using the Jasco FTIR-410 spectrophotometer. IR spectrum of drug and excipient recorded using potassium bromide $(\mathrm{KBr})$. To perform FTIR pallet method is used.

Melting point; Melting point of API was recorded using melting point apparatus (Veego). Capillary process was utilized to perform the test ${ }^{[11,12]}$.

\section{Construction of calibration curve:}

Determination of $\lambda \max$ : Weighed amount of tamoxifen was dissolved in buffer solution having $\mathrm{pH} 6.8$ to obtain $100 \mu \mathrm{g} / \mathrm{ml}$ solution. $1 \mathrm{ml}$ solution was removed and diluted up to $10 \mathrm{ml}$ by phosphate buffer solution. $\lambda \max$ determined at 200-400 $\mathrm{nm}$. Calibration curve determined in following two solutions. Calibration curve of tamoxifen in phosphate buffer 6.8 and calibration curve in ethanol.

\section{Formulation and characterization of drug loaded MSN:}

Formulation of MSN: Procedure: Silica nanoparticles were prepared using precipitation method. $1.6 \mathrm{~g}$ of CTAB mixed with $200 \mathrm{ml}$ distilled water and $60 \mathrm{ml}$ ethanol and $3 \mathrm{ml}$ Triethylamine (TEA). Mixture was stirred continuously until clear solution is obtained. 5 $\mathrm{ml}$ TEOS is added drop wise with continuous stirring. Solution is stirred continuously for $24 \mathrm{~h}$. Turbid suspension is centrifuged at $3000 \mathrm{rpm}$ for $30 \mathrm{~min}$. Obtained precipitate is washed with distilled water and then ethanol. Product is air dried.

Drug loading: Solvent evaporation method is utilized for drug loading. Drug is dissolved in ethanol. Silicon dioxide nanoparticles (SiNP) were added to the solution. Solution was stirred for $2 \mathrm{~h}$. Coupling agent (3-Aminopropyl)triethoxysilane (APTES) was added dropwise and further stirred for $2 \mathrm{~h}$. Solvent evaporated during stirring and the product was dried. SiNP stored in air tight containers for further studies.

Optimization of process variables using $3^{2}$ factorial design: $3^{2}$ factorial design was used for formulation of MSN. Concentration of SiNP $\left(\mathrm{x}_{1}\right)$ and concentration of APTES $\left(\mathrm{x}_{2}\right)$ are selected as independent variable. Three levels determined from literature review. Total 9 bathes were prepared. Statistical model is utilized to decide effect of independent variables on dependent variables that is entrapment efficiency (Y \%). Coded values are taken for independent variable. Three levels are taken in coded form that is low (-1), medium (0) and high $(+1)$. Design expert software was used to obtain values of coefficient in equation. II factors (independent variables) and their levels: $X_{1}=\operatorname{SiNP}(g), X_{2}=$ APTES $(\mathrm{ml})$

From literature review concentration of SiNP and APTES determined is as follows. Three levels of factorial design are shown in Table 1.

\section{Characterization of MSN:}

Particle size: Particle size is determined using Malven Zetasizer. Study was performed using water as dispersion medium at $25^{\circ}$.

\% Entrapment efficiency: Amount of tamoxifen encapsulated in MSN was determined using ultraviolet (UV) spectrophotometer. Accurately weighed $10 \mathrm{mg}$ MSNs was liquefied in $10 \mathrm{ml}$ ethanol, extracted in phosphate buffer having $\mathrm{pH} 6.8$, stirred continuously for $30 \mathrm{~min}$ for evaporation of organic solvent. Solution is filtered by Whatman filter paper and analyzed at $237 \mathrm{~nm}$ using UV spectrophotometer. \% entrapment efficiency is calculated using following formula. \% Entrapment efficiency=Amount of drug in nanoparticles/Amount of drug initially added.

Scanning electron microscopy (SEM): Surface morphology of tamoxifen is determined using SEM. Sample was fixed on SEM stub utilizing two sided adhesive tape. Sample is coated with thin layer of gold under vacuum. Sample was analyzed in SEM chamber at $10 \mathrm{kV}$.

FTIR of tamoxifen MSN: FTIR spectra of tamoxifen, tamoxifen MSN were recorded on Jasco FTIR 410 spectrophotometer at room temperature. $\mathrm{KBr}$ pallet technique adopted to analyze IR at resolution of $4 \mathrm{~cm}^{-1}$ over the range of $4000-400 \mathrm{~cm}^{-1}$.

X-ray diffraction (XRD): X-ray diffractometer (Rikagu Miniflex 600) was used to study XRD

TABLE 1: THREE LEVELS OF FACTORIAL DESIGN

\begin{tabular}{lcc}
\hline Coded values & \multicolumn{2}{c}{ Actual values } \\
\hline & $\mathrm{X}_{1}$ & $\mathrm{X}_{2}$ \\
-1 & 100 & 0.2 \\
0 & 200 & 0.35 \\
1 & 300 & 0.5 \\
\hline
\end{tabular}


patterns. Monochromatosized Copper K-alpha $(\mathrm{Cu}$ $\mathrm{K}$-a) radiation $(1.542 \mathrm{~A})$ is used to load the sample and diffraction pattern were recorded in range of $5^{\circ}-50^{\circ}$. Study is performed at voltage of $30 \mathrm{kV}$.

Differential scanning colorimetry (DSC): Differential scanning colorimeter (DSC 7020 Hitachi) was used for the study of MSN and drug. Temperature and enthalpy was calibrated using hermetically sealed aluminum crucibles with heating at constant pace of $10 \%$ min over the temperature range of $20-250^{\circ}$. Further drug and MSN were analyzed, purging nitrogen gas with flow of $50 \mathrm{ml} / \mathrm{min}$ used.

Solubility studies: Solubility study is performed according to technique by Higuchi and Connors. Weighed amount of MSN were dissolved into solvent for $24 \mathrm{~h}$ and then filtered by using Whatman filter paper. Absorption of solution was recorded by using UV spectrophotometer at $237 \mathrm{~nm}$.

\section{Formulation of fast dissolving tablet (FDT):}

Optimized batch was used for formulation of tablet. Four batches of tablet were prepared. Batches are selected by literature review. Direct compression technique was applied for preparation of tablet.

Direct compression: Powder blend was mixed in mortar and pestle. Tablets were prepared using 6 $\mathrm{mm}$ punch and ten station rotary punching machine. Formula for FDT was shown in Table 2.

Evaluation of FDT: Pre compression evaluation of FDT: Bulk density, tapped density, Hausner's ratio, compressibility index, angle of repose and all these tests are performed.
Post compression studies: Thickness, hardness, friability, weight variation test, drug content, solubility study, in vitro drug release, these are the various studies performed in post compression studies.

\section{RESULTS AND DISCUSSION}

Authentication of drug is performed using melting point, FTIR and UV spectroscopy. Excipient was authenticated by FTIR method. All studies confirmed purity of drug (fig. 1). Melting point of drug was detected at $138-141^{\circ}$. It is found within standard melting point range ${ }^{[13-15]}$.

Standard solution of tamoxifen was scanned on UV spectrophotometer within the ranges of 200-400 nm. An absorption maximum of drug was detected at 237 $\mathrm{nm}$. Readings for calibration curve of tamoxifen in ethanol is shown in fig. 2.

Optical characteristics for calibration curve of tamoxifen in ethanol are shown in Table 3. Equation line: $y=m x+c, y=0.978 x+0.009$. Standard calibration curve was obtained by plotting concentration vs. absorbance. Graph is linear for ranges from $0.2-1 \mu / \mathrm{ml}$. Table 3 shows the standard values of tamoxifen. These values are used for calculation of in vitro drug release and drug content.

TABLE 2: FORMULA FOR FAST DISSOLVING TABLET

\begin{tabular}{lcccc}
\hline Ingredients & $\mathbf{F}_{1}$ & $\mathbf{F}_{2}$ & $\mathbf{F}_{3}$ & $\mathbf{F}_{4}$ \\
\hline MSN & 40 & 40 & 40 & 40 \\
Sodium Starch Glycolate (SSG) & 2 & 4 & 6 & 8 \\
Microcrystalline cellulose & 24 & 22 & 20 & 18 \\
Mannitol & 50 & 50 & 50 & 50 \\
Magnesium stearate & 2 & 2 & 2 & 2 \\
Talc & 2 & 2 & 2 & 2 \\
Total & 120 & 120 & 120 & 120 \\
\hline
\end{tabular}

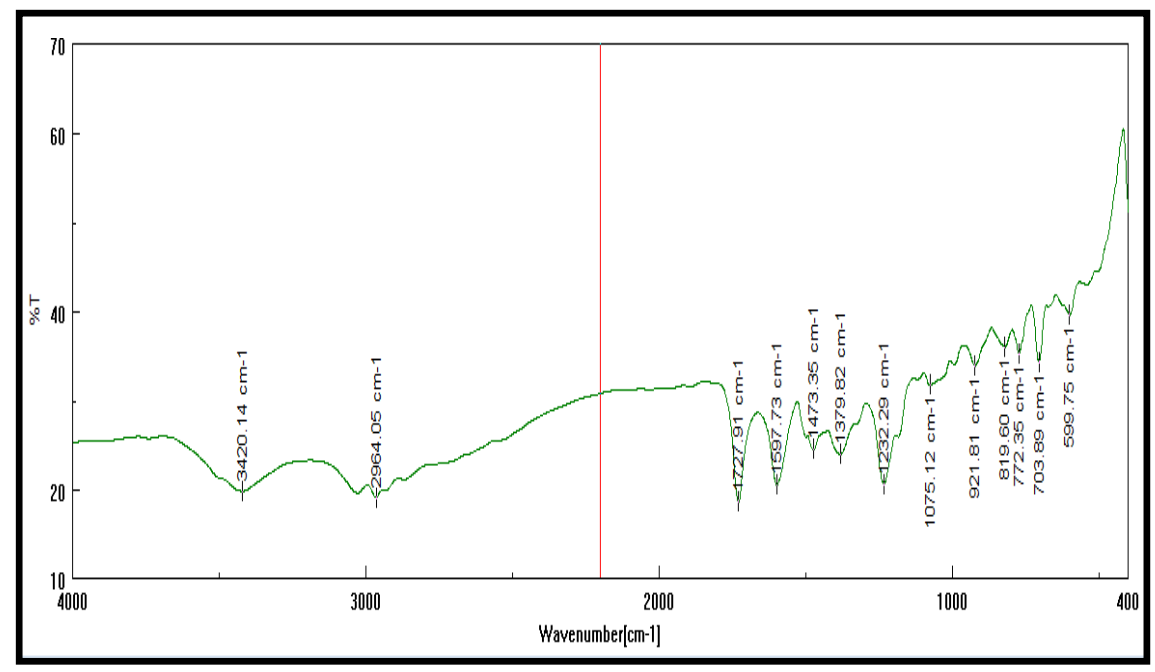

Fig. 1: FTIR of drug 
Calibration curve of tamoxifen in Phosphate Buffered Saline (PBS) pH 6.8 is shown in fig. 3 and optical characteristics for calibration curve of tamoxifen in PBS pH 6.8 are shown in Table 4.

MSN were prepared successfully as per procedure given. Nine batches of drug loaded MSN were prepared successfully.

$3^{2}$ full factorial designs were used for determination of batches. Batches were evaluated at three levels and total nine combinations obtained. To generate equation $\%$ entrapment efficiency is taken as response that is dependent variables. This is used to generate predictor equation with independent variables (SiNP and APTES) which showed all values are within limit and also shows that the given model is fitted to optimize \% entrapment efficiency. Design expert version 12 model was used to obtain values of coefficient in equation.

$\%$ entrapment efficiency from all batches was used to generate predictor equation with independent variables as concentration of SiNP (mg) and concentration of APTES (ml). Optimization of batches was carried out depending upon results obtained. Three levels of factorial design were shown in Table 5.

$3^{2}$ full factorial design layout was given in Table 6. Responses of all batches were recorded in Table 6. From the results, optimized batch was detected Batch No. F7. From the design, optimized concentration was found as concentration of SiNP at maximum level $(X=+1)$ and concentration of APTMS at low level $(X=-1)$.

Results of \% entrapment efficiency is given in Table 7 where Mean \pm Standard deviation (SD) $(n=3)$ and fit statistics is given in Table 8 .

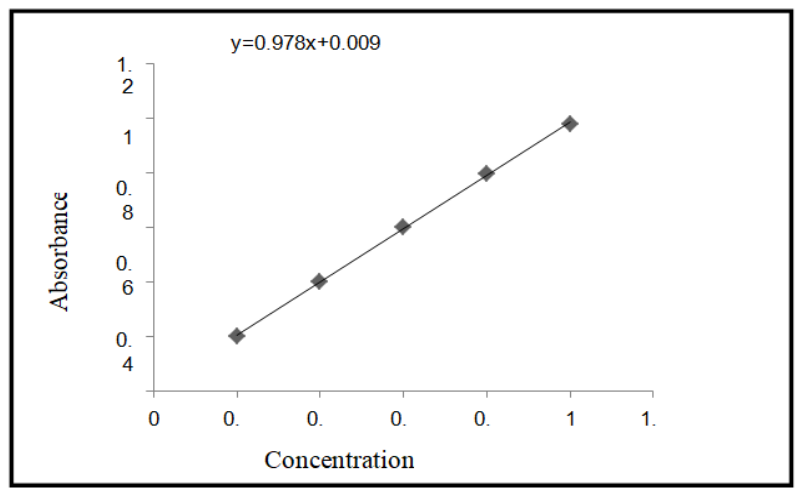

Fig. 2: Calibration curve in ethanol

TABLE 3: OPTICAL CHARACTERISTICS FOR CALIBRATION CURVE OF TAMOXIFEN IN ETHANOL

\begin{tabular}{ll}
\hline Characteristic & Value \\
\hline Correlation coefficient & 0.999 \\
Slope & 0.978 \\
Intercept & 0.009 \\
\hline
\end{tabular}

Final equation in terms of coded factors

$\%$ Entrapment efficiency $=+52.99+26.12 * \mathrm{~A}-9.40$ B. Final equation in terms of actual factors \% Entrapment efficiency $=+22.68890+0.26150 * \mathrm{SiNP}-62.64444$ APTES. Optimum concentration of independent variables is given in Table 9. \% Entrapment efficiency of nine batches is given in Table 7. To determine the effect of independent variables $2 \mathrm{D}$ and $3 \mathrm{D}$ plots were constructed. Factorial design shows all values are within limits. $p$ value is less than 0.5 hence it is significant. Actual and predicted R2 value shows difference of less

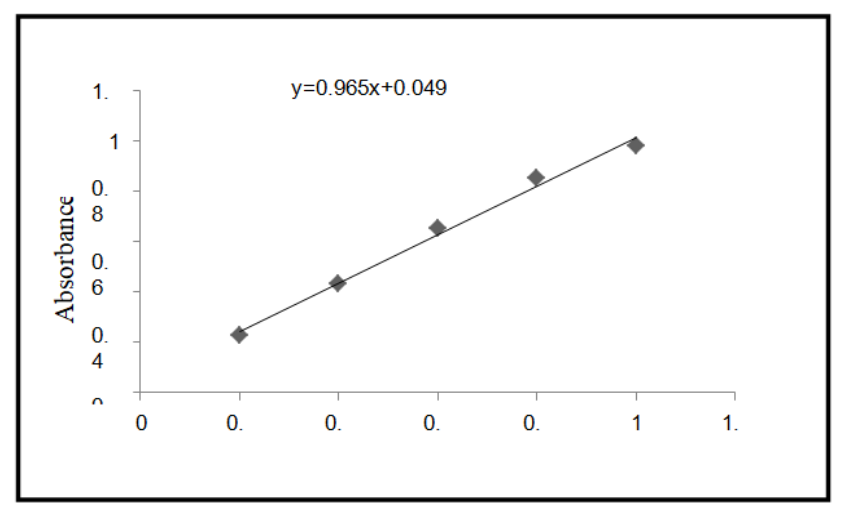

Fig. 3: Calibration curve in PBS pH 6.8

TABLE 4: OPTICAL CHARACTERISTICS FOR CALIBRATION CURVE OF TAMOXIFEN IN PBS PH 6.8

\begin{tabular}{lcc}
\hline S. No. & Characteristic & Value \\
\hline 1 & Correlation coefficient & 0.9959 \\
2 & Slope & 0.965 \\
3 & Intercept & 0.049 \\
\hline Mean \pm SD $(n=3)$ & &
\end{tabular}

TABLE 5: THREE LEVELS OF FACTORIAL DESIGN

\begin{tabular}{lcc}
\hline Coded values & \multicolumn{2}{c}{ Actual values } \\
\hline & $\mathrm{X}_{1}$ & $\mathrm{X}_{2}$ \\
-1 & 100 & 0.2 \\
0 & 200 & 0.35 \\
1 & 300 & 0.5 \\
\hline
\end{tabular}

TABLE 6: $3^{2}$ FULL FACTORIAL DESIGN LAYOUT

\begin{tabular}{lcc}
\hline Batch No. & \multicolumn{2}{c}{ Variable level in coded form } \\
\hline & $X_{1}$ & $X_{2}$ \\
F1 & $-1(100)$ & $-1(0.20)$ \\
F2 & $-1(100)$ & $0(0.35)$ \\
F3 & $-1(100)$ & $+1(0.50)$ \\
F4 & $0(200)$ & $-1(0.20)$ \\
F5 & $0(200)$ & $0(0.35)$ \\
F6 & $0(200)$ & $+1(0.50)$ \\
F7 & $+1(300)$ & $-1(0.20)$ \\
F8 & $+1(300)$ & $0(0.35)$ \\
F9 & $+1(300)$ & $+1(0.50)$ \\
\hline
\end{tabular}


than 0.2 , hence it is reasonable. $2 \mathrm{D}$ and $3 \mathrm{D}$ plots shows that high amount of nanoparticles and low amount of binding agent shows high entrapment efficiency. As per equation, $\mathrm{A}$ has positive effect and $\mathrm{B}$ has negative effect on response. This shows the increase in entrapment efficiency as increase in amount of SiNP and decrease in amount of APTES. Reason could be consumption of active bonding sites by APTES. \% entrapment efficiency was ranged from 17.61-88.29 \% of all the experimental runs.

Particle size is important characteristic for good drug delivery. Good tuning of particle size is important for drug. Particle size is determined using Malvern Zetasizer. According to fig. 4 particle size was detected at $164.5 \mathrm{~nm}$.

\begin{tabular}{|c|c|c|c|}
\hline $\begin{array}{l}\text { TABLE 7: } \\
\text { EFFICIENCY }\end{array}$ & RESULTS & OF $\%$ & ENTRAPMENT \\
\hline Batch No. & & \multicolumn{2}{|c|}{ \% Entrapment efficiency } \\
\hline F1 & & & 33.05 \\
\hline F2 & & & 29.53 \\
\hline F3 & & & 17.61 \\
\hline F4 & & & 63.1 \\
\hline F5 & & & 57.09 \\
\hline F6 & & & 39.68 \\
\hline F7 & & & 88.29 \\
\hline F8 & & & 77.82 \\
\hline F9 & & & 70.77 \\
\hline
\end{tabular}

Mean \pm SD $(n=3)$

TABLE 8: FIT STATISTICS

\begin{tabular}{lc}
\hline \multicolumn{2}{c}{ Fit statistics } \\
\hline Standard Deviation & 2.97 \\
Mean & 52.99 \\
coefficient of variation (\% CV) & 5.6 \\
$\mathrm{R}^{2}$ & 0.9887 \\
Adjusted R & \\
Predicted R & 0.9849 \\
Adequate Precision & 0.9774 \\
\hline
\end{tabular}

SEM shows surface morphology of tamoxifen is found as per fig. 5. Morphology shows that MSN has a spherical structure, uniform shape with smooth surface. FTIR spectra of tamoxifen MSN is shown in fig. 6. XRD (Rikagu Miniflex 600) was utilized to study nature of MSN. Fig. 7 shows XRD patterns of MSN. XRD graph of MSN shows broad peaks and absence of sharp peaks, this indicated amorphous nature of MSN. This indicates that, drug was in amorphous or non-crystalline form and it was loaded successfully in MSN. Solubility of tamoxifen and MSN was detected at 0.020 and 0.120 respectively in water, 0.032 and 0.165 in PBS having pH 6.8. Tamoxifen is a biopharmaceutical classification system (BCS) class II drug hence it is having low water solubility. From the above results, it is concluded that solubility of drug increased when loaded into MSN. Study shows that MSN act as solubility enhancer (Table 10).

Batch F7 were selected for formulation of fast dissolving tablet. Further batches were prepared according to Table 6. Pre compression studies are performed successfully and results are given in Table 11. All studies show results within standard limit.

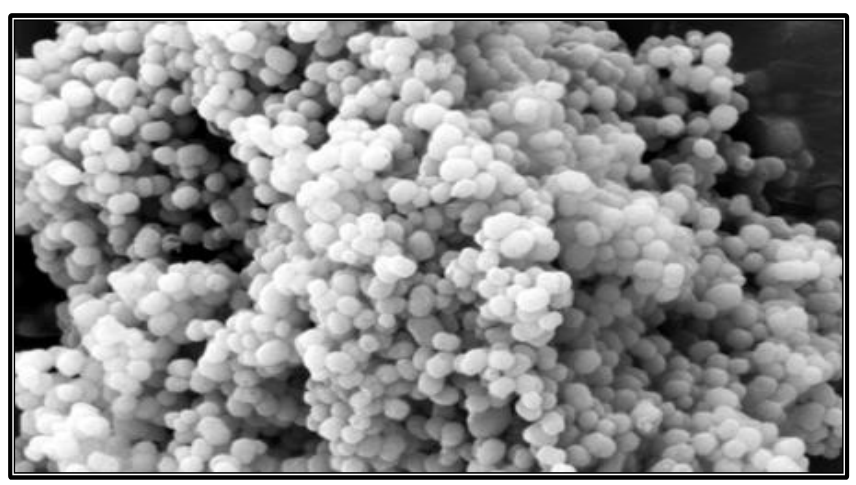

Fig. 4: Particle size of nanoparticles

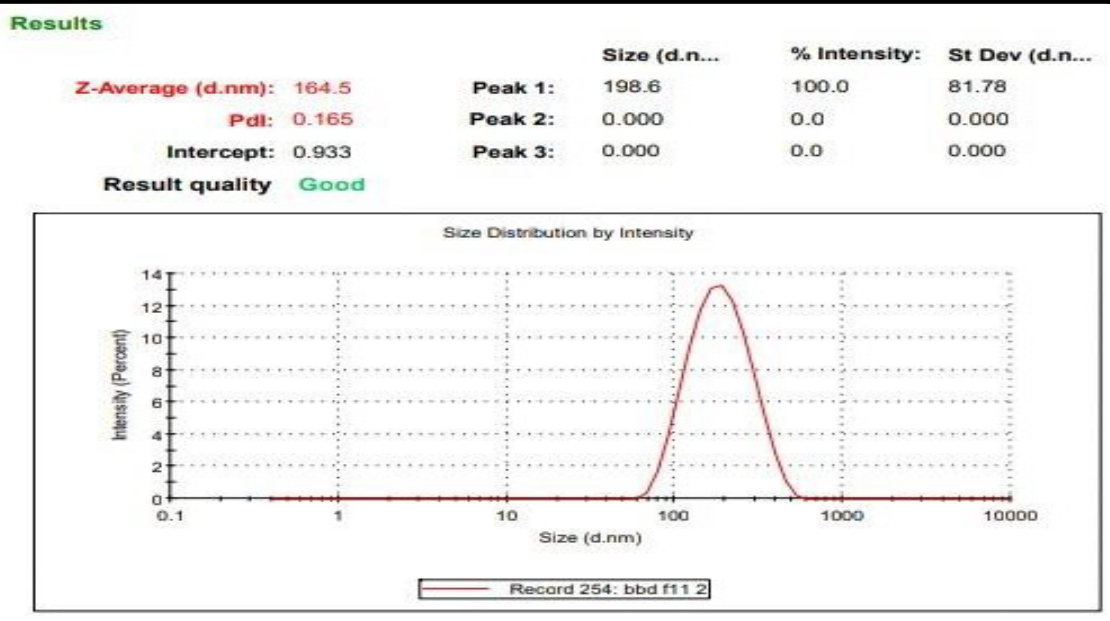




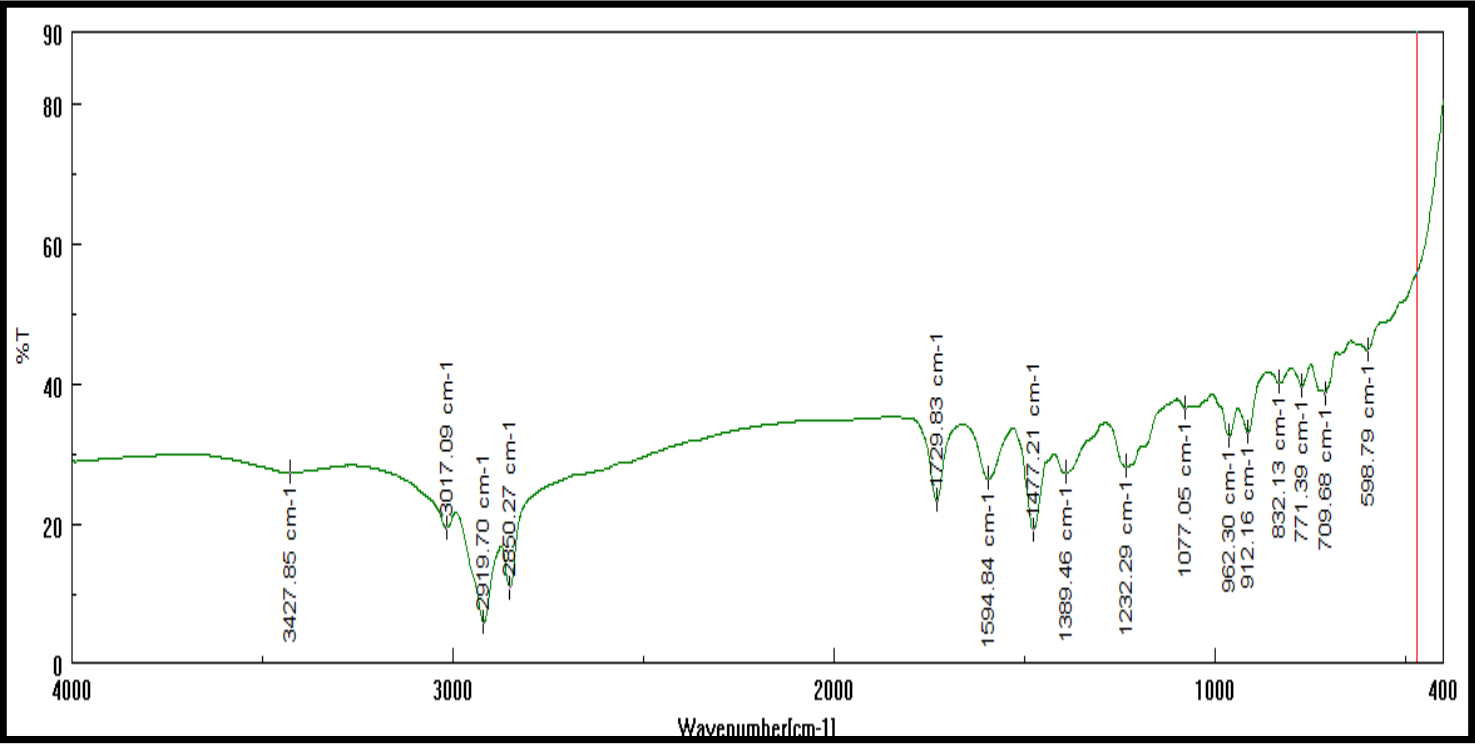

Fig. 6: FTIR of tamoxifen MSN

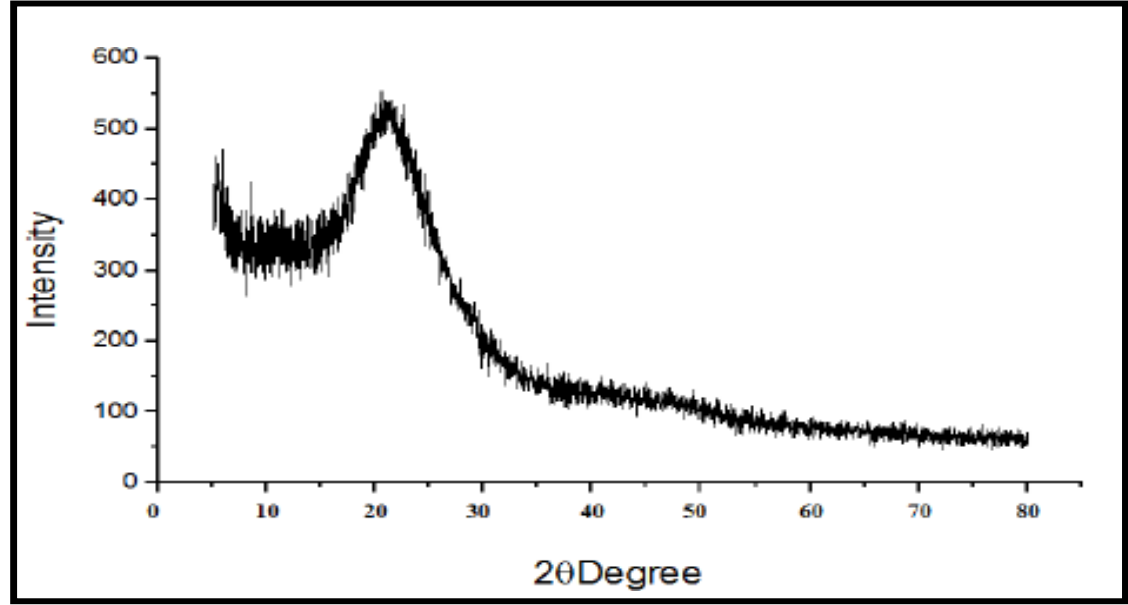

Fig. 7: Results of XRD patterns

\section{TABLE 9: OPTIMUM CONCENTRATION OF INDEPENDENT VARIABLES}

\begin{tabular}{lc}
\hline Concentration & Value \\
\hline Concentration of SiNP $(\mathrm{mg})$ & 300 \\
Concentration of APTES $(\mathrm{ml})$ & 0.2 \\
\hline
\end{tabular}

Post compression studies are performed successfully and results are given in Table 12. All studies show results within standard limit.

Results of percent drug release are recorded in Table 13 and fig. 8. All batches shows drug release between 0.03-95.58\%. Batch D shows highest drug release that is $95.58 \%$ at $150 \mathrm{~s}$. It is because of high concentration of super disintegrant. This batch contains $8 \mathrm{~g}$ of super disintegrant. Sodium starch glycolate is used as super disintegrant. Study was carried out up to $150 \mathrm{~s}$.

The present work is formulation and evaluation of MSN loaded FDT of tamoxifen. Aim of work was to
TABLE 10: RESULTS FOR SOLUBILITY STUDIES

\begin{tabular}{lccc}
\hline \multicolumn{4}{c}{ Solubility $(\mathrm{mg} / \mathrm{ml})$} \\
\hline S. No. & Formulation & Water & PBS pH 6.8 \\
1 & Tamoxifen & 0.02 & 0.032 \\
2 & MSN & 0.12 & 0.165 \\
\hline
\end{tabular}

enhance solubility and dissolution of drug. Tamoxifen is the anti-cancerous drug. It is widely used for therapy of breast carcinoma. Tamoxifen is BCS class II drug which is having problem with solubility. It is having very low solubility in water and is soluble in ethanol, methanol. Now a day's nanoparticles technique is extensively utilized to improve solubility of anticancerous drugs. FDT is used to achieve immediate action of drug and to avoid first pass metabolism of drug. Due to this reasons more quantity of API reaches to site of action. Hence, both nanoparticles and FDT resulted in increased solubility and immediate action which results in increased bioavailability ${ }^{[16]}$. 
TABLE 11: PRE COMPRESSION EVALUATION OF FAST DISSOLVING TABLET

\begin{tabular}{lccccc}
\hline Batch & Bulk density & Tapped density & Hausner's ratio & Compressibility index & Angle of repose \\
\hline A & $0.139 \pm 0.001$ & $0.1413 \pm 0.000$ & $1.0153 \pm 0.01$ & $2.46 \pm 1.06$ & $27.016 \pm 0.263$ \\
B & $0.120 \pm 0.000$ & $0.1213 \pm 0.000$ & $1.0033 \pm 0.003$ & $1.63 \pm 0.543$ & $20.83 \pm 0.219$ \\
C & $0.127 \pm 0.000$ & $0.132 \pm 0.000$ & $1.0123 \pm 0.005$ & $1.276 \pm 0.497$ & $14.01 \pm 1.366$ \\
D & $0.117 \pm 0.000$ & $0.120 \pm 0.000$ & $1.018 \pm 0.008$ & $2.1483 \pm 0.488$ & $11.3 \pm 4.11$ \\
\hline
\end{tabular}

TABLE 12: POST COMPRESSION STUDIES OF FAST DISSOLVING TABLET

\begin{tabular}{lcccccc}
\hline Batch & Thickness & Hardness & Friability & Weight variation & \% Drug content & Disintegration time \\
\hline A & $2.5 \pm 0.000$ & $2.76 \pm 0.033$ & $0.99 \pm 0.05$ & $119.15 \pm 0.35$ & $96.88 \pm 0.20$ & $280.66 \pm 0.66$ \\
B & $2.3 \pm 0.095$ & $2.56 \pm 0.088$ & $0.83 \pm 0.08$ & $119.31 \pm 0.552$ & $97.68 \pm 0.03$ & $224.66 \pm 0.33$ \\
C & $2.4 \pm 0.033$ & $2.66 \pm 0.082$ & $0.58 \pm 0.00$ & $120.45 \pm 0.724$ & $97.16 \pm 0.03$ & $176.00 \pm 1$ \\
D & $2.3 \pm 0.0882$ & $2.33 \pm 0.066$ & $0.33 \pm 0.46$ & $120.15 \pm 0.477$ & $97.78 \pm 0.03$ & $126.00 \pm 0.57$ \\
\hline
\end{tabular}

TABLE 13: RESULTS FOR IN VITRO DRUG RELEASE STUDY

\begin{tabular}{lcccc}
\hline Time & A & B & C & D \\
\hline 0 & 0 & 0 & 0 & 0 \\
15 & 0 & $00.03 \pm 0.01$ & $00.04 \pm 0.00$ & $00.05 \pm 0.00$ \\
30 & $00.23 \pm 0.00$ & $01.95 \pm 0.01$ & $01.90 \pm 0.03$ & $02.70 \pm 0.22$ \\
45 & $02.91 \pm 0.01$ & $04.84 \pm 0.16$ & $05.00 \pm 0.04$ & $09.98 \pm 0.09$ \\
60 & $06.04 \pm 0.01$ & $09.74 \pm 0.14$ & $17.49 \pm 0.26$ & $12.95 \pm 0.09$ \\
75 & $11.88 \pm 0.02$ & $15.52 \pm 1.30$ & $26.97 \pm 0.30$ & $20.57 \pm 0.11$ \\
90 & $18.62 \pm 0.04$ & $24.45 \pm 1.31$ & $38.66 \pm 0.28$ & $30.41 \pm 0.10$ \\
105 & $26.28 \pm 0.06$ & $39.81 \pm 2.32$ & $52.89 \pm 0.33$ & $42.51 \pm 0.10$ \\
120 & $35.75 \pm 0.09$ & $47.00 \pm 2.12$ & $68.78 \pm 0.34$ & $56.83 \pm 0.08$ \\
135 & $46.98 \pm 0.11$ & $62.80 \pm 4.89$ & $86.78 \pm 0.36$ & $74.74 \pm 0.07$ \\
150 & $60.02 \pm 1.75$ & $80.71 \pm 1.98$ & $95.58 \pm 0.06$ \\
\hline
\end{tabular}

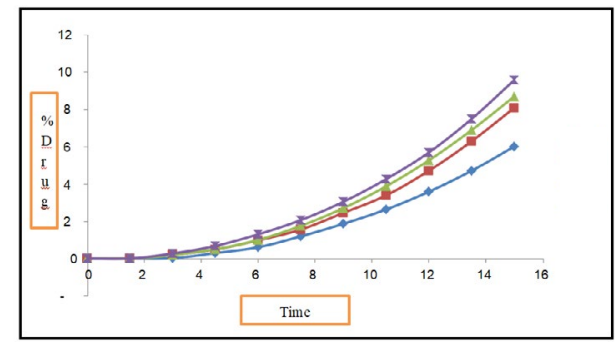

Fig. 8: Percentage drug release

Batch D shows rapid drug release which is possible due to MSN. Main aim of project is to increase solubility and rapid release of drug, which was achieved.

\section{Acknowledgements:}

None

\section{Conflict of Interests:}

The authors declared no conflict of interest.

\section{REFERENCES}

1. Narayan R, Nayak UY, Raichur AM, Garg S. Mesoporous silica nanoparticles: A comprehensive review on synthesis and recent advances. Pharmaceutics 2018;10(3):118.

2. Mehmood A, Ghafar H, Yaqoob S, Gohar UF, Ahmad B. Mesoporous silica nanoparticles: a review. J Dev Drugs 2017;6(02):1000174.

3. Bharti C, Nagaich U, Pal AK, Gulati N. Mesoporous silica nanoparticles in target drug delivery system: A review. Int $\mathrm{J}$ Pharm Investig 2015;5(3):124.

4. Rahane RD, Rachh PR. A review on fast dissolving tablet. J Drug Deliv Ther 2018;8(5):50-5.

5. Masih A, Kumar A, Singh S, Tiwari AK. Fast dissolving tablets: A review. Int J Curr Pharm Res 2017;9:8-18.

6. Gupta AK, Mittal A, Jha KK. Fast dissolving tablet-A review. Pharma Innov 2012;1(1):1-8.

7. Moreira AF, Dias DR, Correia IJ. Stimuli-responsive mesoporous silica nanoparticles for cancer therapy: A review. Microporous Mesoporous Mater 2016;236:141- 57.

8. Kumar S, Malik MM, Purohit R. Synthesis methods of mesoporous silica materials. Mater Today Proc 2017;4(2): 350-7.

9. Heel RC, Brogden RN, Speight TM, Avery GS. Tamoxifen: a review of its pharmacological properties and therapeutic use in the treatment of breast cancer. Drugs 1978;16(1):1-24.

10. Ahmad I. Tamoxifen a pioneering drug: An update on the therapeutic potential of tamoxifen derivatives. Eur J Med Chem 2018;143:515-31.

11. Tamoxifen. Pubchem.ncbi.nlm.nih.gov; 2004.

12. Tamoxifen. Drugbank, DB00675; 2020.

13. Rowe RC, Sheskey P, Quinn M. Handbook of pharmaceutical excipients. Libros Digitales-Pharmaceutical Press; 2009:663-6.

14. Shaskey P, Marine Q. MCC, Handbook of Pharmaceutical Excipients; 2009;129-132.

15. Shaskey P, Marine Q. Sodium starch glycolate, Handbook of Pharmaceutical Excipients; 2009:152-4.

16. Wang W, Fang C, Wang X, Chen Y, Wang Y, Feng W, et al. Modifying mesoporous silica nanoparticles to avoid the metabolic deactivation of 6-mercaptopurine and methotrexate in combinatorial chemotherapy. Nanoscale 2013;5(14):624953.

January-February 2021

Indian Journal of Pharmaceutical Sciences

38 